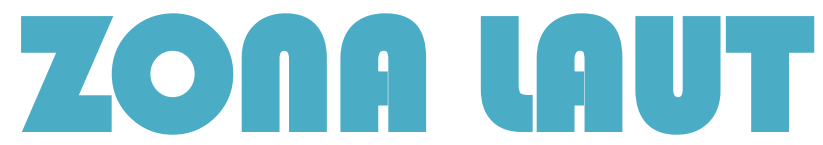

\title{
PERANCANGAN SISTEM HPWH (HEAT PUMP WATER HEATER) PADA KM. MERATUS KARIMATA
}

\author{
*Andriyan, Urip Prayogi dan Dwisetiono \\ Fakultas Teknik dan Ilmu Kelautan, Universitas Hang Tuah Surabaya \\ *yanslankers94@gmail.com
}

\begin{abstract}
Abstrak
Kebutuhan air panas di kapal merupakan salah satu fasilitas yang harus didapatkan oleh ABK (Anak Buah Kapal) selama menjalankan tugasnya di kapal. KM. Meratus Karimata merupakan salah satu kapal yang menyediakan air panas sebagai fasilitas untuk ABK. Sistem pemanas pada kapal ini masih menggunakan sistem pemanas EHHW (Electric Heating Hot Water) yang kemudian akan dirubah dengan sistem HPWH (Heat Pump Water Heater). Kebutuhan air panas ini didasari oleh MLC (Marine Labour Convention) mengenai penyediaan recreational facilities pada akomodasi deck. Penyediaan air panas ini perlu dilakukan perhitungan dan perancangan, yang pertama dilakukan yaitu perhitungan seluruh komponen penunjang pendistribusian. Kemudian didapatkan data kebutuhan pompa dengan daya $0.504 \mathrm{Kw}$, valve, keran shower, keran wastafel, sambungan pipa, dan pipa SCH 40 dengan diameter 3/4" dan 1". Setelah itu dilakukan desain perancangan dengan menggunakan bantuan software. Setelah dilakukan perancangan, lalu dilakukan perhitungan biaya komponen dengan rincian harga valve Rp 10.129.000, pipa Rp 5.186.000, sambungan pipa Rp 1.751.000, pompa supplay Rp 1.150.000, HPWH 95.300.000. Harga dari EHHW dan HPWH ini terdapat selisih Rp 21.300.000 dimana lebih mahal HPWH. Tetapi dalam perhitungan konsumsi bahan bakar lebih hemat HPWH dengan data konsumsi bahan bakar HPWH 0,11 liter/jam dengan biaya Rp 1.249/jam, sedangkan konsumsi bahan bakar untuk EHHW 0,77 liter/jam dengan biaya Rp 10.116/jam.
\end{abstract}

Kata Kunci: HPWH (Heat Pump Water Heater), EHHW (Electric Heating Hot Water), Fasilitaas Air Hangat, Desain dan Perancangan, Perencanaan Biaya.

\begin{abstract}
The need for hot water on a ship is one of the facilities that must be obtained by the crew while carrying out their duties on the KM. Meratus Karimata is one of the ships that provide hot water as a facility for crew members. The heating system on this ship still uses the EHHW (Electric Heating Hot Water) heating system which will then be changed to the HPWH (Heat Pump Water Heater) system. This hot water need is based on the MLC (Marine Labor Convention) regarding the provision of recreational facilities on deck accommodation. The provision of hot water needs to be calculated and designed. The first thing to do is to calculate all distribution support components. Then the data for the needs of pumps with a power of $0.504 \mathrm{Kw}$, valves, shower taps, sink taps, pipe connections, and SCH 40 pipes with a diameter of $3 / 4$ "and 1 " are obtained. After that, the design is carried out using software assistance. After the design is carried out, the calculation of component costs is carried out with details of the valve price of IDR 10,129,000, pipe IDR 5,186,000, pipe connection IDR 1,751,000, supply pump IDR 1,150,000, HPWH 95,300,000. The price of EHHW and HPWH is a difference of IDR 21,300,000, which is more expensive for HPWH. However, in the calculation of fuel consumption, HPWH is more efficient with HPWH fuel consumption data of 0.11 liters/hour at a cost of Rp.1,249 / hour, while fuel consumption for EHHW is 0.77 liters/hour at a cost of Rp.10,116/ hour.
\end{abstract}

Keywords: HPWH (heat pump water heater), EHHW (Electric Heating Hot Water), Hot water facilities, Design and design, Cost planning

copyright is published under Lisensi Creative Commons Atribusi 4.0 Internasional. 


\section{PENDAHULAN}

Sistem pemanas air pada kapal memiliki banyak pilihan diantaranya menggunakan thermal water heater dan boiler. Pemilihan sistem pemanas air di kapal diperlukan karena sistem pemanas ini merupakan salah satu kebutuhan pokok crew kapal. Sedangkan sistem pemanas sendiri juga memerlukan sumber tenaga untuk menghasilkan beban panas. Bila terjadi kesalahan pemilihan sistem pemanas maka dapat menambah biaya operasional kapal [1]. KM. Meratus Karimata sendiri merupakan jenis kapal general cargo yang digunakan untuk wilayah pelayaran Surabaya ke Samarinda. Dalam hal ini KM. Meratus Karimata memiliki sebuah sistem pemanas air yang disebut dengan EHHW (Electric Heating Hot Water). Sistem pemanas ini berguna untuk memenuhi kebutuhan harian ABK (Anak Buah Kapal) antara lain digunakan untuk mandi, minum, masak hal ini di perkuat oleh MLC Regulation 3.12006 accomodation dan recreational facilities [2].

EHHW ini memiliki sumber tenaga dari energi listrik. Permasalahan terjadi pada salah satu sistem pemanas air di KM. Meratus Karimata, sistem ini beroperasi 24 jam pada saat kondisi kapal dalam keadaan main engine mati pun (dalam keadaan lego jangkar atau sandar di pelabuhan) kapal ini menggunakan unit auxillary engine untuk mensuplai energi listrik ke seluruh peralatan listrik yang ada di kapal selama kapal sandar [3]. Hal ini dapat mengakibatkan pemborosan pada operasional kapal terutama pada konsumsi listrik. Salah satu penyebab penambahan daya terbesar disebabkan oleh EHHW memiliki sumber tenaga yaitu dari listrik untuk menghidupkan elemen pemanas. Saat ini muncul inovasi baru yakni HPWH (Heat Pump Water Heater) [4]. HPWH adalah alat yang digunakan untuk menghasilkan air panas, dengan biaya listrik yang digunakan lebih hemat dari pada EHHW. HPWH merupakan water heater yang banyak dipakai pada perusahaan komersial karena kelebihannya, yaitu lebih hemat dan lebih efisien [5].

Prinsip kerja HPWH ini hampir sama dengan sistem AC (Air Conditioning) komponen - komponennya pun juga hampir sama [6]. Sehingga dilakukan perhitungan teknis perbandingan spesifikasi pemanas, dan waktu pemanasan untuk masing - masing sistem pemanas, serta dilakukan perhitungan ekonomis agar mendapatkan sistem pemanas yang paling kecil dalam penggunaan daya auxillary engine dan yang paling irit dalam konsumsi bahan bakarnya [7]. Karena karena hal ini memegang peranan penting dalam perancangan dan pemilihan alat alat penukar kalor, sehingga para ahli teknik tidak boleh melupakan hal ini, ketika berhubungan dengan perancangan alat penukar kalor [8]. Dalam penelitian sebelumnya telah didapatkan perhitungan secara teknis untuk penggunaan sistem HPWH.

Selanjutnya setelah didapatkannya perhitungan yang dibutuhkan maka dilakukan perancangan sistem HPWH tersebut untuk penerapannya pada KM. Meratus Karimata. Perancangan yang akan dilakukan ini dibantu dengan menggunakan software agar mempermudah dalam proses perancangan. Setelah dilakukan perancangan kemudian dilakukan perhitungan dan perbandingan ekonomis. Perhitungan dan perbandingan dalam segi ekonomis ini meliputi biaya pemasangan. Dari hasil tersebut, kemudian dapat disimpulkan sistem manakah yang lebih ekonomis dalam penerapannya di KM. Meratus Karimata.

\section{METODE}

Studi literatur diperoleh dari berbagai referensi diantaranya adalah buku, internet, artikel-artikel dan jurnal yang berhubungan dengan perancangan, teori ekonomis, dan sistem water heater di kapal. Dengan mempelajari literaturliteratur yang ada dapat menunjang penelitian ini diharapakan pada tahap selanjutnya penulis dapat mengetahui tahapan selanjutnya untuk mendapatkan nilai yang dibutuhkan untuk sistem water heater di KM. Meratus Karimata.

\subsection{Data KM. Meratus Karimata}

Principal Particulars LOA (Length Over All) 119,9 meter, BMLD (Breadth Moulded) 21,8 meter, DMLD (Depth Moulded) 7,3 meter dan Dead weight 8.180 Ton.

\subsection{Perancangan Sistem HPWH dengan Bantuan Software}

Pada tahap ini dilakukan perancangan sistem HPWH dengan menggunakan bantuan software agar lebih mudah dalam proses perancangan dan agar lebih presisi dalam proses perancangannya. Sebelum melakukan perancangan ini dilakukan terlebih dahulu pengukuran pada rancangan asli yang ada pada KM. Meratus Karimata. Setelah dilakukan pengukuran barulah dilakukan penggambaran awal berupa sketsa pada kertas 
untuk mempermudah penulis dalam memperoleh data awal. Setelah itu dilakukan perhitungan skala untuk didapatkannya gambar rancangan yang sesuai dengan etika dalam menggambar teknik. Kemudian setelah sketsa digambar dan telah dilakukan perhitungan untuk mendapatkan skala yang pas barulah perancangan dilakukan di computer dengan menggunakan bantuan software.

Proses pengerjaan perancangan sistem ini diawali dengan pengambilan data di perusahaan dan permohonan ijin agar dapat dilakuknnya pengambilan data di lapangan. Kemudian setelah perusahaan memberi ijin, maka dilakukannya survey terlebih dahulu. Setelah dilakukannya survey, kemudian dilakukan pengukuran dan peritungan ukuran ruangan kamar mesin.

Proses perancangan ini dibantu dengan menggunakan software AutoCAD agar proses perancangan lebih mudah dan apabila terjadi kesalahan saat proses menggambar akan dengan mudah merubah. Software AutoCAD yang digunakan adalah AutoCAD 2017 dengan layout 2D. Pengerjaan penggambaran sistem ini tetap dengan kaidah-kaidah dan aturan dalam menggambar teknik, agar saat proses pengerjaan dilapangan dapat dipahami dengan mudah oleh pekerja.

\subsection{Perhitungan Biaya}

Dalam perancangan sistem ini ada beberapa kebutuhan material seperti pipa, sambungan pipa, valve, kran dan lain sebagainya. Adapun perincian kebutuhan material sebagai berikut:

1. Pipa

Ada dua ukuran pipa yang digunakan pada perancangan sistem yaitu pipa SCH 40 dengan ukuran 3/4" dan 1".

a. Kebutuhan pipa SCH 40 ukuran 3/4", Pada deck A kebutuhan pipa 17,3 Meter, Pada deck B kebutuhan pipa 37,5 Meter, Pada deck C kebutuhan pipa 41,3 Meter Pada kamar mesin ke deck atas 21 Meter, total kebutuhan pipa SCH 40 ukiran 3/4" adalah 117,1 Meter

b. Kebutuhan pipa ukuran 1" hanya berada di kamar mesin menuju ke deck atas, total kebutuhan panjang pipa 11,25 Meter

2. Sambungan pipa

Ada beberapa sambungan pipa yang digunakan untuk penyambungan cabang pipa dalam pendistribusian air panas.

a. Knee atau elbow ukuran 3/4" Pada deck A kebutuhan elbow 8 pcs, Pada deck B kebutuhan elbow 26 pcs, Pada deck C kebutuhan elbow, 24 pcs, total kebutuhan sejumlah 58 pcs

b. Tee ukuran 3/4" Pada deck A kebutuhan Tee 8 pcs, Pada deck B kebutuhan Tee 5 pcs, Pada deck C kebutuhan Tee 5 pcs, total kebutuhan sejumlah 18 pcs

c. Knee atau elbow ukuran 1" 6 pcs

d. Tee ukuran 1" 3 pcs

e. Sambungan Y ukuran $3 / 4$ " 9 pcs

3. Valve

Valve disini digunakan untuk menutup dan membuka aliran air panas dari tanki sistem HPWH menuju ke tiap deck di kapal untuk kebutuhan MCK. Ada beberapa jenis valve yang digunakan pada sistem ini, yaitu:

a. Butterfly valve, total kebutuhan 3 pcs

b. SDNR globe valve, total kebutuhan 2 pcs

c. Ball valve, total kebutuhan 26 pcs

d. Globe valve, total kebutuhan 5 pcs

e. Kran air untuk shower Pada deck A kebutuhan kran 3 pcs, Pada deck B kebutuhan kran 4 pcs, Pada deck C kebutuhan kran 4 pcs, total kebutuhan sejumlah 11 pcs

f. Kran air untuk wastafel Pada deck A kebutuhan kran 3 pcs, Pada deck B kebutuhan kran 4 pcs, Pada deck C kebutuhan kran 4 pcs, total kebutuhan sejumah 11 pcs.

\section{HASIL DAN PEMBAHASAN}

Dari hasil perhitungan diatas didapatkan hasil data kebutuhan material dalam perancangan satu sistem water heater sebagai berikut: 
Tabel 1. Kebutuhan pipa

\begin{tabular}{ccc}
\hline Jenis pipa & Ukuran & $\begin{array}{c}\text { Jumlah } \\
(\mathrm{m})\end{array}$ \\
\hline SCH 40 & $3 / 4$ inch & 117.1 \\
& 1 inch & 11.25 \\
\hline
\end{tabular}

Tabel 2. Kebutuhan sambugan pipa

\begin{tabular}{ccc}
\hline Jenis sambungan & Ukuran & $\begin{array}{c}\text { Jumlah } \\
(\mathrm{pcs})\end{array}$ \\
\hline Knee/elbow & $3 / 4$ inch & 58 \\
Tee & 1 inch & 6 \\
& $3 / 4$ inch & 18 \\
Y & 1 inch & 3 \\
& $3 / 4$ inch & 9 \\
& 1 inch & - \\
\hline
\end{tabular}

Tabel 3. Kebutuhan valve

\begin{tabular}{ll}
\hline Jenis valve & Jumlah $(\mathrm{pcs})$ \\
\hline Butterfly valve & 3 \\
SDNR globe valve & 2 \\
Ball valve & 26 \\
Globe valve & 5 \\
\hline
\end{tabular}

Tabel 4. Kebutuhan kran air

\begin{tabular}{ll}
\hline Jenis kran air & Jumlah (pcs) \\
\hline Kran shower & 11 \\
Kran wastafel & 11 \\
\hline
\end{tabular}

Dari jumlah kebutuhan material diatas didapatkan perhitungan kebutuhan biaya dalam perencanaan perancangan sistem tersebut sebagai berikut:

Tabel 5. Perhitungan biaya pipa

\begin{tabular}{lllll}
\hline Jenis pipa & Ukuran & Harga & $\begin{array}{l}\text { Kebutuhan } \\
(\mathrm{m})\end{array}$ & Total pembiayaan \\
\hline SCH 40 & 3/4 inch & Rp 226.000 & 117.1 & Rp 4.520.000 \\
& 1 inch & Rp 333.000 & 11.25 & $\begin{array}{l}\text { Rp 666.000 } \\
\text { Jumlah }\end{array}$ \\
\hline
\end{tabular}

Tabel 6. Perhitungan biaya valve

\begin{tabular}{llll}
\hline Jenis valve & Harga & Kebutuhan (pcs) & Total pembiayaan \\
\hline Butterfly valve & Rp 385.000 & 3 & Rp 1.155.000 \\
SDNR globe & Rp 285.000 & 2 & Rp 570.000 \\
valve & & & \\
Ball valve & Rp 198.000 & 26 & Rp 5.148.000 \\
Globe valve & Rp 319.000 & 5 & Rp 1.595.000 \\
Jumlah & & & Rp 8.468.000 \\
\hline
\end{tabular}

Tabel 7. Perhitungan kran air

\begin{tabular}{llll}
\hline Jenis kran & Harga & Kebutuhan $(\mathrm{pcs})$ & Total pembiayaan \\
\hline Kran shower & Rp 76.000 & 11 & Rp 836.000 \\
Kran wastafel & Rp 75.000 & 11 & Rp 825.000 \\
Jumlah & & & Rp 1.688.000 \\
\hline
\end{tabular}


Tabel 8. Perhitungan unit inti

\begin{tabular}{lccl}
\multicolumn{1}{c}{ Jenis unit } & Harga & Kebutuhan $(\mathrm{pcs})$ & \multicolumn{1}{c}{ Total pembiayaan } \\
\hline Pompa supplay & Rp 1.150 .000 & 1 & Rp 1.150 .000 \\
HPWH & Rp 95.300.000 & 1 & Rp 95.300.000 \\
& Jumlah & & Rp 96.450.000 \\
\hline
\end{tabular}

\section{KESIMPULAN}

Dalam penelitian ini didapatkan 2 kesimpulan yaitu:

1. Proses perancangan antara sistem EHHW dan HPWH tidak jauh berbeda dari kedua sistem tersebut. Karna perancangan sistem yang baru ini bertujuan sebagai penggambaran ulang seluruh sistem pendistribusian air panas di KM. Meratus Karimata. Perbedan yang lebih spesifik antara kedua sistem tersebut adalah pada unit water heaternya, sistem water heater pada EHHW menjadi satu kesatuan dalam sistem berbentuk tabung, sedangkan sistem water heater pada HPWH dibagi menjadi 2 unit yaitu unit tank dan unit kondensor yang merupakan heat exchanger.

2. Sedangkan untuk pembiayaan perancangan awal pada sistem HPWH ini memang lebih mahal daripada EHHW. Terdapat selisih harga kurang lebih Rp 21.300.000, tetapi untuk pembiayaan dalam segi operasional terbilang lebih hemat untuk sistem HPWH, telah diperhitungkan pada penelitian sebelumnya yang dilakukan oleh Moeh. Irfan Rifalo yang membuktikan bahwa Kebutuhan daya dan bahan bakar masing-masing sistem pemanas KM. Meratus Karimata diperoleh EHHW kebutuhan bahan bakar 0.77 liter/jam, dengan biaya Rp. 10.116 dan HPWH Kebutuhan bahan bakar 0.11 liter/jam, dengan biaya Rp. 1.429 Apabila ditinjau dari waktu pemanasan awal, sistem pemanas HPWH lebih efisien untuk KM. Meratus Karimata.

\section{UCAPAN TERIMA KASIH}

Terima kasih kepada bapak dosen yang telah membimbing saya dan kepada Universitas Hang Tuah, dan terima kasih kepada pihak Universitas Hasanudin yang telah mengijinkan saya untuk mempublikasikan jurnal penelitian saya.

\section{DAFTAR PUSTAKA}

[1] Rifaldo, M Irfan.2019. “Analisa Teknis Sistem Hpwh (Heat Pump Water Heater) Pada Km. Meratus Karimata “. SKRIPSI. Surabaya.

[2] Chairbowo Fajri \& Ichsani Djatmiko.2017. "Rancang Bangun dan Studi Eksperimen Alat Penukar Panas untuk Memanfaatkan Energi Refrigerant Keluar Kompresor AC sebagai Pemanas Air pada $\mathrm{ST} / \mathrm{D}=8$ dengan Variasi Volume Air". Jurnal Teknik ITS, 5(2).

[3] Jokosisworo, S.2012." Studi Komparasi Pipa SCH 40 Galvanize dengan SCH 40 Non Galvanize pada Sistem Pipa Ballast Dikaji dari Segi Teknis dan Ekonomis" Jurnal Teknik Perkapalan UNDIP, 7(3).

[4] Mulyadi.1990.” Analisa Dalam Perhitungan Biaya Untuk Membangun Sebuah Perusahaan Dari Segi Ekonomi” Jogjakarta.

[5] Kalinci Yildiz \& Hepbasli Arif.2009. "A review of heat pump water heatingsystems ". Renewable and Sustainable Energy Reviews, 13(6-7), 1211-1229

[6] Andriyan.2018." Tugas Merancang IV" [LAPORAN]. Surabaya

[7] Binus, Ibnu.2010." Feasibility Theory Studi Kelayakan Bisnis" Palu.

[8] Neksa Petter \& Zakeri Reza.1998. "CO2-heat pump water heater: characteristics, system design and experimental results “. International Journal of refrigeration, 21(3), 172-179. 